\title{
The quality of Medicaid and Medicare data obtained from CMS and its contractors: implications for pharmacoepidemiology
}

Charles E. Leonard ${ }^{1,2^{*}}$, Colleen M. Brensinger ${ }^{1,2}$, Young Hee Nam, ${ }^{1,2}$, Warren B. Bilker ${ }^{1,2}$, Geralyn M. Barosso ${ }^{3}$, Margaret J. Mangaali ${ }^{1,2}$ and Sean Hennessy ${ }^{1,2,4}$

\begin{abstract}
Background: Administrative claims of United States Centers for Medicare and Medicaid Services (CMS) beneficiaries have long been used in non-experimental research. While CMS performs in-house checks of these claims, little is known of their quality for conducting pharmacoepidemiologic research. We performed exploratory analyses of the quality of Medicaid and Medicare data obtained from CMS and its contractors.
\end{abstract}

Methods: Our study population consisted of Medicaid beneficiaries (with and without dual coverage by Medicare) from California, Florida, New York, Ohio, and Pennsylvania. We obtained and compiled 1999-2011 data from these state Medicaid programs (constituting about 38\% of nationwide Medicaid enrollment), together with corresponding national Medicare data for dually-enrolled beneficiaries. This descriptive study examined longitudinal patterns in: dispensed prescriptions by state, by quarter; and inpatient hospitalizations by federal benefit, state, and age group. We further examined discrepancies between demographic characteristics and disease states, in particular frequencies of pregnancy complications among men and women beyond childbearing age, and prostate cancers among women.

Results: Dispensed prescriptions generally increased steadily and consistently over time, suggesting that these claims may be complete. A commercially-available National Drug Code lookup database was able to identify the dispensed drug for $95.2-99.4 \%$ of these claims. Because of co-coverage by Medicare, Medicaid data appeared to miss a substantial number of hospitalizations among beneficiaries $\geq 45$ years of age. Pregnancy complication diagnoses were rare in males and in females $\geq 60$ years of age, and prostate cancer diagnoses were rare in females.

Conclusions: CMS claims from five large states obtained directly from CMS and its contractors appeared to be of high quality. Researchers using Medicaid data to study hospital outcomes should obtain supplemental Medicare data on dual enrollees, even for non-elders.

Trial Registration: Not applicable.

Keywords: Centers for Medicare and Medicaid Services (U.S.), Data accuracy, Databases as a topic, International Classification of Diseases, Medicaid, Medicare, Pharmacoepidemiology

\footnotetext{
* Correspondence: celeonar@mail.med.upenn.edu

${ }^{1}$ Center for Pharmacoepidemiology Research and Training, Department of Biostatistics, Epidemiology, and Informatics, Perelman School of Medicine, University of Pennsylvania, 423 Guardian Drive, Philadelphia, PA 19104-4865, USA

${ }^{2}$ Center for Clinical Epidemiology and Biostatistics, Department of Biostatistics, Epidemiology, and Informatics, Perelman School of Medicine, University of Pennsylvania, 423 Guardian Drive, Philadelphia, PA 19104-4865, USA

Full list of author information is available at the end of the article
} 


\section{Background}

United States (US) Medicaid data are widely used for epidemiologic, health services, and policy research [1-3]. Given the potential public health importance of findings arising from such studies, it is critical to understand the quality of the underlying data. Medicaid data are available to researchers via multiple pathways, including from the Centers for Medicare and Medicaid Services (CMS-via its contractors), commercial data vendors, and potentially direct from individual states. Academic, governmental, and non-profit researchers most commonly acquire these data from CMS. In recent years, CMS has made concerted efforts to improve the quality of its raw and research-transformed enrollment and claims files $[4,5]$. Their initiatives [4] have led to quality standards, external benchmarking, and publication of file specifications and anomaly reports [6]. While researchers can use these complex technical documents to review validation measures, key summary statistics, and unusual patterns in state data (if documented), there remains a need for a higher-level, overarching examination of data quality.

Researchers often recognize the importance of evaluating the completeness and validity of particular measures of exposure, outcome, and other explanatory factors that will be relied upon in a particular study [7]. Yet, few first examine overarching data quality. Given this, we examined broad indicators of potential error in US Medicaid and Medicare data acquired from CMS and its contractors.

\section{Methods}

Over 14 calendar years (2003-2016), supported by grants from the US National Institutes of Health, we requested and obtained Medicaid Analytic Extract (MAX) files [8] from 1999-2011 (hereafter referred to as file years) for California, Florida, New York, Ohio, and Pennsylvania. We selected these states for study since they are geographically diverse and have a combined prevalent enrollment of nearly 26 million persons, or about $38 \%$ of the nationwide Medicaid program [9]. For Medicaid beneficiaries in these states with at least some period of Medicare coverage (i.e., dual enrollees), we further requested and obtained their Medicare claims from the following research identifiable files (RIFs): Medicare Provider Analysis and Review (MedPAR-including short stay hospital, long stay hospital, and skilled nursing facility), Prescription Drug Event (PDE-from Medicare Part D's 2006 implementation onward), Carrier, and Outpatient [10]. Therefore, the population under study included Medicaid beneficiaries of five large states with and without dual coverage by Medicare. Data were obtained directly from CMS and two different CMS research data distribution contractors over the 14-calendar year period (CMS [Baltimore, Maryland] from 2003-2005,
Acumen [Burlingame, California] from 2006-2008, and Buccaneer/General Dynamics [Falls Church, Virginia] from 2009-2016).

We were able to use identifiers provided in the data to track unique beneficiaries longitudinally. Using the MAX Personal Summary file, we first identified beneficiaries without a gap in Medicaid enrollment in a given file year-acknowledging that not all individuals had the same beginning date of their initial enrollment. We then determined the proportion of such beneficiaries without a gap in Medicaid enrollment in each subsequent file year. This served to quantify the persistence of Medicaid enrollment in beneficiaries over long periods of time.

We then graphically summarized several important parameters to assess data completeness and validity. Because our principal use of these data is for pharmacoepidemiologic research, we first looked for unexplained variation in the number of dispensed prescriptions per quarter in each state, which might suggest incomplete prescription data for certain time periods [11]. Relatedly, we also measured the proportion of MAX Prescription and Medicare PDE claims for which the billed National Drug Code (NDC) corresponded to a record in a commercially-available NDC database (Lexicon Plus v.02.01.2016, Cerner Multum: Denver, Colorado). For billed NDCs without a matching record in Lexicon Plus, we used the following alternate sources to identify such products: RxNorm (US National Library of Medicine: Bethesda, Maryland); then state Medicaid drug lists; and then the NDC Directory (US Food and Drug Administration: Silver Spring, Maryland).

We also plotted the ratio of hospitalizations to beneficiary population size in each state, stratified by age group. We did this first using MAX Inpatient data alone, then adding hospitalizations identified by supplementing with Medicare data (MedPAR short stay hospital RIF) to determine the importance of obtaining Medicare data on dual enrollees. To avoid doublecounting hospitalizations recorded in both Medicaid and Medicare, we included only one hospitalization per beneficiary per day.

We also examined the frequency of obvious diagnostic miscoding by comparing quarterly counts of claims with a diagnosis of Complications of Pregnancy, Childbirth, and Puerperium (International Classification of Diseases, 9th revision, clinical modification [ICD-9-CM] codes $630-677$ and subcodes) among females age $<60$, females age $\geq 60$, and males. Finally, we compared quarterly counts of claims with a diagnosis of prostate cancer (ICD-9-CM: 185, 233.4, 222.2, 236.5, and subcodes) between males and females.

Medicaid and Medicare data access was governed by a data use agreement executed between The Trustees of the University of Pennsylvania and CMS. The University 
of Pennsylvania's institutional review board approved the activities described herein.

\section{Results}

Among 15,627,762 beneficiaries identified in file year 1999, 12,649,367 (80.9\%) had no enrollment gaps through the year's end. About $14 \%$ of these beneficiaries remained continuously enrolled through the end of 2011 - a period of 13 years. Table 1 presents proportions for interim time points and also for beneficiaries newlyidentified as having a full year of continuous enrollment post-1999. Raw counts of beneficiaries are presented in Additional file 1: Table S1.

Figure 1 depicts quarterly prescriptions dispensed per state. Dispensed prescriptions generally increased consistently over time, except for Ohio in which they decreased then plateaued during 2006-2010 (see Discussion). The proportion of dispensed prescriptions in which a claim NDC matched a record in Lexicon Plus was $95.2-98.4 \%$ in MAX Prescription and $99.2-99.4 \%$ in Medicare PDE data, depending on file year. See Additional file 1: Figure S1 for state-specific trends. Claim NDCs not identified by Lexicon Plus were most commonly for condoms and diabetes care supplies (Additional file 1: Table S2).

Figure 2 depicts the annual rate of hospitalization in each state, stratified by age group and federal benefit, considering Medicaid as primary and Medicare as supplemental. As expected, many hospitalizations in older adults would have been missed if one relied exclusively on Medicaid data. Surprisingly, many hospitalizations in the 45-65 year age group would have been missed if one relied exclusively on Medicaid data. There was a nearly monotonic increase in the rate of hospitalization by age, beginning with the 6-14 year age group.
Additional file 1: Figures S2 and S3 depict quarterly counts of claims with a diagnosis of Complications of Pregnancy, Childbirth, and Puerperium and with a diagnosis of prostate cancer, respectively. Encouragingly, there were few pregnancy-related claims in females age $\geq 60(130,987$ [0.2\% of pregnancy-related claims]) and in males (197,337 [0.3\% of pregnancy-related claims]), and few prostate cancer claims in females $(24,839$ [0.9\% of prostate cancerrelated claims]). Instances of apparent miscoding were less common in inpatient than outpatient claims ( 0.3 vs. $0.4 \%$ overall, respectively).

\section{Discussion}

Medicaid and Medicare data provided by CMS and its contractors are widely utilized in epidemiologic, policy, and health services research. However, errors in data can lead to incorrect scientific inferences and evaluations of public policy. Encouragingly, the CMS dataset under study appeared to be of high quality.

This dataset provides one an ability to follow a surprisingly large number of beneficiaries without gaps in Medicaid enrollment over long periods of time, despite a large proportion of beneficiaries under study having at least some period of disenrollment. This is important to researchers wishing to study long-term effects of medical products or policy decisions, for example.

Further, dispensed prescriptions generally increased steadily and consistently over time, suggesting that these claims from the Medicaid programs and file years under study may be complete. An exception may be represented by a dip in Ohio's prescription claims from 2006-2010, a trend likely driven by managed care expansion $[12,13]$. During this time, pharmacy benefits in Ohio were carved-in to managed care and the state was

Table 1 Proportion of beneficiaries without a gap in Medicaid enrollment in each subsequent file year following their initial file year devoid of a gap, using 1999-2011 Medicaid Analytic Extract Personal Summary files from CA, FL, NY, OH, and PA

\begin{tabular}{|c|c|c|c|c|c|c|c|c|c|c|c|c|c|}
\hline & 1999 & 2000 & 2001 & 2002 & 2003 & 2004 & 2005 & 2006 & 2007 & 2008 & 2009 & 2010 & 2011 \\
\hline 1999 & 100 & 58 & 47 & 41 & 35 & 30 & 27 & 23 & 21 & 19 & 17 & 15 & 14 \\
\hline 2000 & & 100 & 56 & 42 & 31 & 14 & 12 & 10 & 8 & 7 & 6 & 5 & 5 \\
\hline 2001 & & & 100 & 50 & 33 & 21 & 17 & 13 & 11 & 9 & 8 & 7 & 6 \\
\hline 2002 & & & & 100 & 48 & 28 & 21 & 17 & 13 & 11 & 10 & 9 & 8 \\
\hline 2003 & & & & & 100 & 41 & 27 & 20 & 15 & 13 & 11 & 9 & 8 \\
\hline 2004 & & & & & & 100 & 52 & 34 & 26 & 12 & 10 & 9 & 7 \\
\hline 2005 & & & & & & & 100 & 44 & 28 & 18 & 15 & 13 & 11 \\
\hline 2006 & & & & & & & & 100 & 44 & 25 & 20 & 17 & 14 \\
\hline 2007 & & & & & & & & & 100 & 39 & 28 & 22 & 18 \\
\hline 2008 & & & & & & & & & & 100 & 56 & 42 & 34 \\
\hline 2009 & & & & & & & & & & & 100 & 50 & 34 \\
\hline 2010 & & & & & & & & & & & & 100 & 48 \\
\hline 2011 & & & & & & & & & & & & & 100 \\
\hline
\end{tabular}




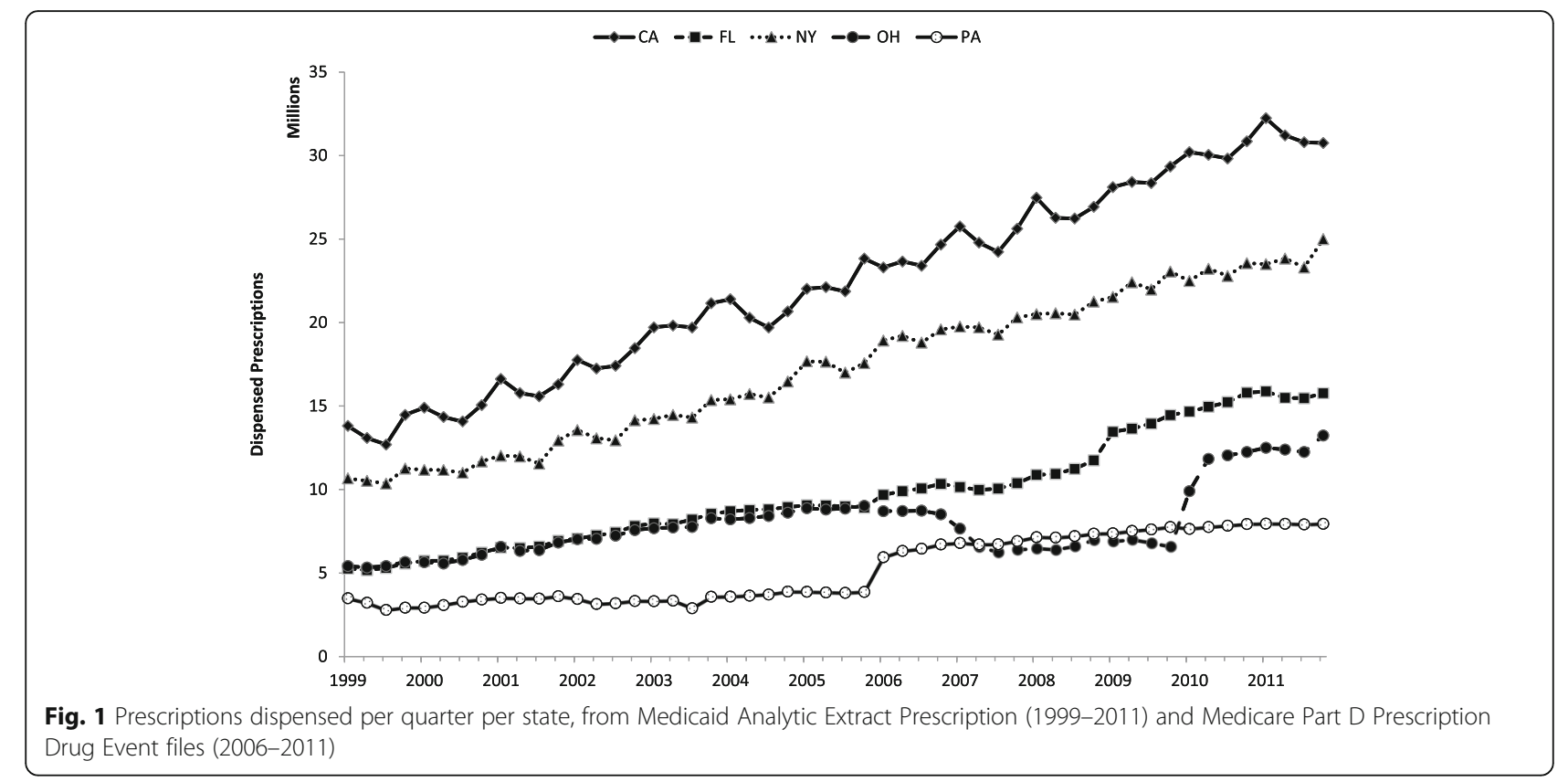

undergoing their Medicaid Management Information System replacement project [14]. Therefore, such claims were not reported to CMS. This explainable "missingness" is in contrast to our prior finding of unexplained variation in prescription claims over time in CMS data obtained from a commercial vendor [11]. We were also encouraged that 95-99\% of the prescription claims billed for an NDC identifiable in Lexicon Plus, a commonly-used drug lookup database; this is important since the NDC is the principal method for identifying dispensed drugs in US claims data. That being said, researchers interested in identifying non-drug products (e.g., diabetes supplies) billable to CMS may wish to use an alternative or multiple NDC lookup databases to ensure complete capture.

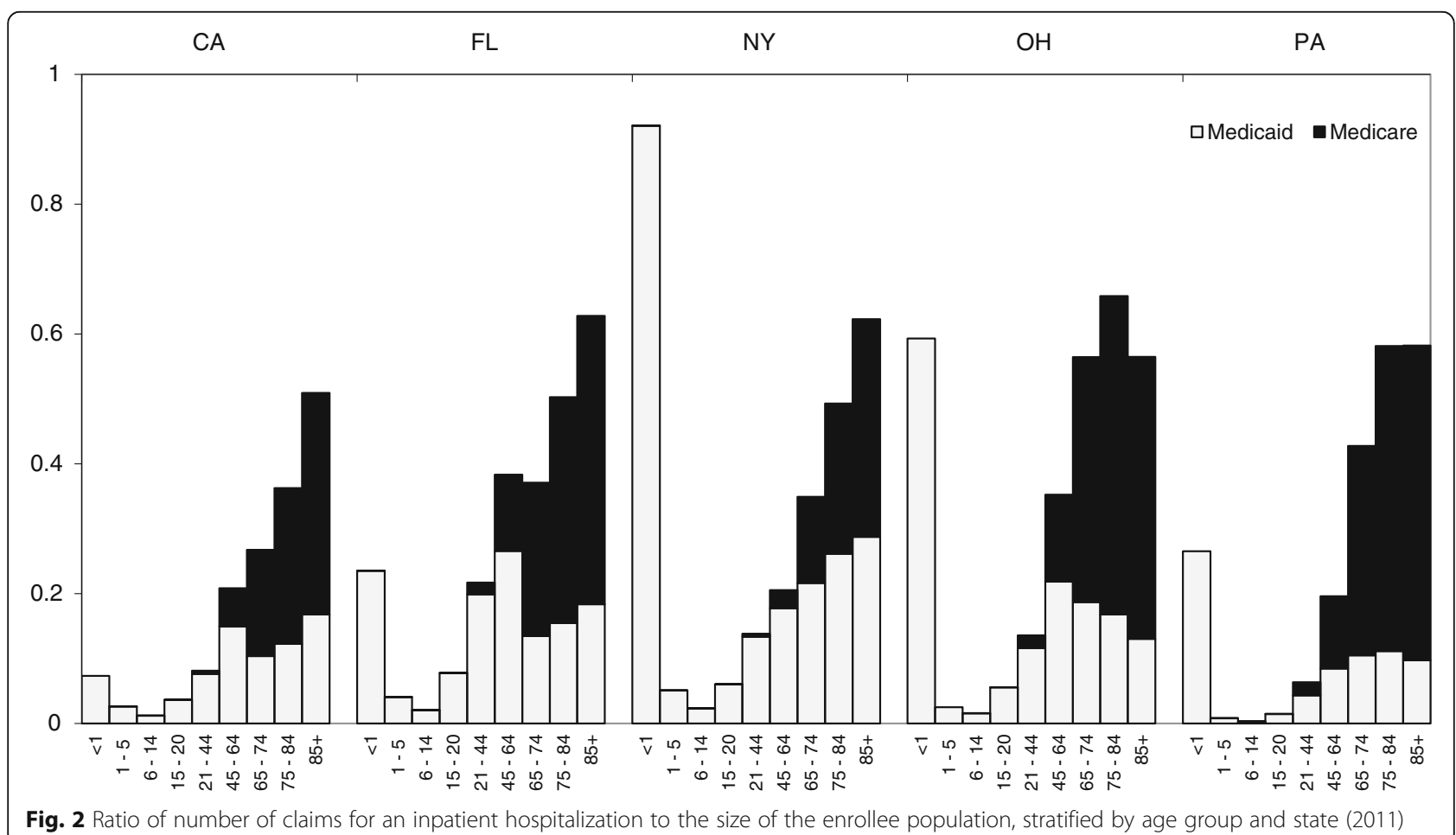

Fig. 2 Ratio of number of claims for an inpatient hospitalization to the size of the enrollee population, stratified by age group and state (2011) 
The pattern of hospitalization rates by age group within Medicaid claims alone is similar to prior findings $[11,15]$, in which the apparent rate increases up to age 64 , then declines at age 65 . This implausible pattern is probably an artifact of benefit structures, in which hospitalizations of Medicaid beneficiaries age $\geq 65$ who are enrolled in Medicare are covered by Medicare (the primary payer for dual enrollees). Notably, reliance on Medicaid claims alone would have also missed a substantive number of hospitalizations in non-elders, especially among persons age 45-64. This may be due to the fact that non-elders account for $\sim 40 \%$ of all dual enrollees and have poorer health than older adults enrolled in Medicare alone [16]. These findings reinforce the importance of obtaining corresponding Medicare claims of dual enrollees in studies using Medicaid data, even if limited to a non-elder adult population [11, 15]. High rates of hospitalization in beneficiaries age $<1$ year appear to be driven by diagnostic coding of liveborn infant status in newborns.

We examined two crude markers of apparent diagnostic miscoding (i.e., pregnancy complications in males and older females, prostate cancer in females) and found that gross inconsistencies were uncommon. While reassuring, this finding does not eliminate the need to formally evaluate the validity and performance metrics of specific health outcomes of interest. Fortunately, it is now possible, for research purposes, to access primary medical records to validate diagnoses from inpatient and outpatient Medicaid and Medicare claims-with retrieval rates ranging from $29-89 \%$ for inpatient charts and $27-66 \%$ for outpatient charts [17-27].

We are unaware of a single standard approach to examine the general validity of a health services database. Therefore, we selected metrics that were broadly applicable, intuitively appealing, easy to measure, and easy to interpret. This is consistent with our prior work in this area [15] and in alignment with fit-for-use quality assessment components described by Kahn et al. [28] and Brown et al. [29] The findings herein build upon our prior work by: a) including an additional 11 file years of data, thereby allowing us to examine long-term trends in data quality and quantify the persistence of the Medicaid population; b) including Medicare PDE data, since its implementation in 2006; and c) assessing the consistency in quality across multiple data contractors. While other researchers have examined some broad measures of CMS data quality [30, 31], their datasets under study were from the 1980s and predated the current model by which CMS prepares data for and provides data to researchers.

Big data is a large part of the future of healthcare [32]. However, the use and analysis of big data must be based on accurate and high-quality information-a necessary condition for generating value from big data [33]. Medicaid data available from CMS have tremendous potential utility for research that will ultimately improve the health of the public. Performing exploratory data analyses, such as that conducted herein, is an important first step in using administrative databases. Of course, failure to identify problems in the course of such analyses is no guarantee that the data are valid and complete-especially when selected quality metrics represent a tiny fraction of metrics that could be examined (e.g., trends in claims for ambulatory care encounters, trends in claims for laboratory orders [29]). Given the potential for error in administrative data due to variation in individual states' program structures and data processing practices, such as diagnostic miscoding, the analyses presented herein can provide a baseline level of understanding of such data.

\section{Conclusion}

In conclusion, we broadly examined the quality of thirteen file years of Medicaid and Medicare data from five large states obtained via CMS and its contractors. The findings are reassuring to researchers-millions of beneficiaries are able to be studied over time without gaps in enrollment, prescription claims appear to be complete and their NDCs identifiable, and obvious diagnostic miscoding is rare. Researchers using Medicaid data to study hospital outcomes should obtain supplementary Medicare data on dual enrollees for studies of persons age 45 years and above.

\section{Additional file}

Additional file 1: Supplemental data consisting of three additional figures and two additional tables. (DOCX $97.2 \mathrm{~kb}$ )

\section{Abbreviations}

CMS: Centers for Medicare and Medicaid Services; ICD-9-CM: International Classification of Diseases 9th Revision Clinical Modification; MAX: Medicaid Analytic Extract; MedPAR: Medicare Provider Analysis and Review; NDC: National Drug Code; PDE: Prescription Drug Event; RIF: Research Identifiable File; US: United States

\section{Acknowledgements}

The authors wish to thank the following biostatistics and computer programming staff from the University of Pennsylvania for their assistance on this project: Qing Liu, Min Du, and Craig W. Newcomb.

\section{Funding}

The project described was supported by the Perelman School of Medicine at the University of Pennsylvania's Center for Pharmacoepidemiology Research and Training and the following grants from the US National Institutes of Health: R01AG025152; and R01DK102694. The federal funders had no role in the study beyond comments received during the grant review process.

\section{Availability of data and materials}

Data that support the findings of this study are available from CMS. Restrictions apply to the availability of these data-used under a data use agreement between the Trustees of the University of Pennsylvania and CMS for the current study - and therefore are not publically available. However, 
data may be available from the authors upon a reasonable request and with permission from CMS.

\section{Authors' contributions}

CEL and SH formulated the research question. CEL and SH designed the study. SH acquired the data. CMB, WBB, and YN analyzed the data. CMB, WBB, and YN provided analytic tools. All authors were involved in data interpretation. CEL drafted the manuscript. All authors critically revised the manuscript. All authors read and approved the final manuscript. SH secured funding for the study.

\section{Author's information}

Dr. Leonard is a pharmacoepidemiologist in the Center for Pharmacoepidemiology Research \& Training at the University of Pennsylvania's Perelman School of Medicine (Philadelphia, Pennsylvania). Dr. Leonard's interests and experience lie in the conduct of observational comparative effectiveness and safety studies using administrative data, particularly Medicaid and Medicare claims. He has published on topics such as sudden cardiac arrest, drug interactions, drug-induced renal disease, drug-induced respiratory disease, the genetics of drug metabolism, instrumental variable techniques, and the hybrid ecologic-epidemiologic trend-in-trend research design, among others. Dr. Leonard also serves as Applied Surveillance Core Co-Leader for the Food and Drug Administration's Sentinel program coordinated by Harvard Pilgrim Health Care Institute-developing and co-developing prospective surveillance plans and protocol-based assessments to facilitate the rapid identification and assessment of safety issues with medical products.

\section{Competing interests}

CEL, CMB, YN, MJM, and SH declare no conflicts of interest. WBB has consulted for Janssen on an unrelated topic. GMB is a Senior Technical Advisor at the Research Data Assistance Center, a CMS contractor (contract \#HHSM-500-2013-00166C) that provides free assistance to academic, government and non-profit researchers interested in using Medicare and/or Medicaid data for their research. The University of Pennsylvania's Center for Pharmacoepidemiology Research and Training receives support for its training programs from Pfizer and the Sanofi Foundation for North America.

\section{Consent for publication}

Not applicable.

\section{Ethics approval and consent to participate}

The University of Pennsylvania's institutional review board approved the activities described herein. Access to Medicaid and Medicare claims used herein was permitted by CMS and governed by a data use agreement.

\section{Publisher's Note}

Springer Nature remains neutral with regard to jurisdictional claims in published maps and institutional affiliations.

\section{Author details}

${ }^{1}$ Center for Pharmacoepidemiology Research and Training, Department of Biostatistics, Epidemiology, and Informatics, Perelman School of Medicine, University of Pennsylvania, 423 Guardian Drive, Philadelphia, PA 19104-4865, USA. ${ }^{2}$ Center for Clinical Epidemiology and Biostatistics, Department of Biostatistics, Epidemiology, and Informatics, Perelman School of Medicine, University of Pennsylvania, 423 Guardian Drive, Philadelphia, PA 19104-4865, USA. ${ }^{3}$ Division of Health Policy and Management, School of Public Health, University of Minnesota, 420 Delaware Street SE, Mayo D355, Minneapolis, MN 55455-0381, USA. ${ }^{4}$ Department of Systems Pharmacology and Translational Therapeutics, Perelman School of Medicine, University of Pennsylvania, 34th Street \& Civic Center Boulevard, Philadelphia, PA 19104-5158, USA.

Received: 13 August 2016 Accepted: 19 April 2017 Published online: 26 April 2017

\section{References}

1. Hennessy S, Freeman CP, Cunningham F. US government claims databases. In: Strom BL, Kimmel SE, Hennessy S, editors. Pharmacoepidemiology. 5th ed. Chichester: Wiley-Blackwell; 2012. p. 209-23.
2. Crystal S, Akincigil A, Bilder S, Walkup JT. Studying prescription drug use and outcomes with Medicaid claims data: strengths, limitations, and strategies. Med Care. 2007;45(10 Supl 2):S58-65.

3. Ray WA. Policy and program analysis using administrative databases. Ann Intern Med. 1997;127(8 Pt 2):712-8.

4. Centers for Medicare \& Medicaid Services. Frequently asked questions. FAQ2455. Available at: https://questions.cms.gov/faq.php?id=5005\&faqld= 2455. Accessed 21 Apr 2017.

5. Centers for Medicare \& Medicaid Services. Details for title: Medicaid Analytic Extract production, enhancement, and data quality MAX-PDQ. Active Projects Report. Available at: https://www.cms.gov/Research-Statistics-Dataand-Systems/Statistics-Trends-and-Reports/ActiveProjectReports/ActiveProjects-Reports-Items/CMS1187450.html. Accessed 21 Apr 2017.

6. Ruttner L, Borck R, Nysenbaum J, Williams S. Medicaid policy brief: guide to MAX data. Math Policy Res Brief. 2015;21:1-10.

7. West SL, Ritchey ME, Poole C. Validity of pharmacoepidemiologic drug and diagnosis data. In: Strom BL, Kimmel SE, Hennessy S, editors. Pharmacoepidemiology. 5th ed. Chichester: Wiley-Blackwell; 2012. p. 757-94.

8. Barosso G. Conducting research with Medicaid claims data videos. 2016. Available at: http://www.resdac.org/training/workshops/intro-medicaid/ media/1. Accessed 21 Apr 2017.

9. Kaiser Family Foundation. Medicaid enrollment by gender. State Health Facts web site. 2015. Available at: http://kff.org/medicaid/state-indicator/ medicaid-enrollment-by-gender/. Accessed 21 Apr 2017.

10. Research Data Assistance Center. RIF Medicare claims. RIF Medicare claims web site. 2016. Available at: http://www.resdac.org/cms-data/file-family/RIFMedicare-Claims. Accessed 21 Apr 2017.

11. Hennessy S, Bilker WB, Weber A, Strom BL. Descriptive analyses of the integrity of a US medicaid claims database. Pharmacoepidemiol Drug Saf. 2003;12(2):103-11.

12. Moody G, Health Policy Institute of Ohio. Ohio Medicaid basics 2007. 2007: 1-23. Available at: http://www.healthpolicyohio.org/wp-content/uploads/ 2014/02/medicaidbasics_2007.pdf. Accessed 21 Apr 2017.

13. The Center for Health Affairs. The evolution of Medicaid managed care in Ohio. 2007:1-12. Available at: https://neohospitals.org/ FinanceAndReimbursement/DataResources. Accessed 21 Apr 2017.

14. Mathematica Policy Research. MSIS State Data Characteristics / Anomalies Report. 2015:1-364. Available at: https:/www.cms.gov/Research-Statistics-Dataand-Systems/Computer-Data-and-Systems/MedicaidDataSourcesGenInfo/MAXValidation-Reports.html. Accessed 21 Apr 2017.

15. Hennessy S, Leonard CE, Palumbo CM, Newcomb C, Bilker WB. Quality of Medicaid and Medicare data obtained through Centers for Medicare and Medicaid services (CMS). Med Care. 2007;45(12):1216-20.

16. The Henry J. Kaiser Family Foundation. Dual Eligibles. Dual Eligibles Tutorial web site. 2012. Available at: http://kff.org/interactive/dual-eligibles-tutorial/. Accessed 21 Apr 2017.

17. Byrne DD, Newcomb CW, Carbonari DM, Nezamzadeh MS, Leidl KB, Herlim M, Yang YX, Hennessy S, Kostman JR, Leonard MB, Localio R, Lo Re 3rd V. Prevalence of diagnosed chronic hepatitis B infection among U.S. Medicaid enrollees, 2000-2007. Ann Epidemiol. 2014;24(6):418-23.

18. Palmsten K, Huybrechts KF, Kowal MK, Mogun H, Hernandez-Diaz S. Validity of maternal and infant outcomes within nationwide Medicaid data. Pharmacoepidemiol Drug Saf. 2014;23(6):646-55.

19. Cook EA, Schneider KM, Robinson J, Wilwert J, Chrischilles E, Pendergast J, Brooks J. Field methods in medical record abstraction: assessing the properties of comparative effectiveness estimates. BMC Health Serv Res. 2014;14:391.

20. Calderwood MS, Kleinman K, Bratzler DW, Ma A, Kaganov RE, Bruce CB, Balaconis EC, Canning C, Platt R, Huang SS, CDC Prevention Epicenters Program, Oklahoma Foundation for Medical Quality. Medicare claims can be used to identify US hospitals with higher rates of surgical site infection following vascular surgery. Med Care. 2014;52(10):918-25.

21. Calderwood MS, Kleinman K, Bratzler DW, Ma A, Bruce CB, Kaganov RE, Canning C, Platt R, Huang SS, Centers for Disease Control and Prevention Epicenters Program, Oklahoma Foundation for Medical Quality. Use of Medicare claims to identify US hospitals with a high rate of surgical site infection after hip arthroplasty. Infect Control Hosp Epidemiol. 2013; 34(1):31-9.

22. Katz JN, Wright EA, Baron JA, Corbett KL, Nti AA, Malchau H, Wright J, Losina E. Predictive value of Medicare claims data for identifying revision of index hip replacement was modest. J Clin Epidemiol. 2011;64(5):543-6. 
23. Hennessy S, Leonard CE, Freeman CP, Deo R, Newcomb C, Kimmel SE, Strom BL, Bilker WB. Validation of diagnostic codes for outpatientoriginating sudden cardiac death and ventricular arrhythmia in Medicaid and Medicare claims data. Pharmacoepidemiol Drug Saf. 2010;19(6):555-62.

24. Hennessy S, Leonard CE, Bilker WB. Researchers and HIPAA. Epidemiology. 2007;18(4):518

25. Lo Re 3rd V, Haynes K, Ming EE, Wood Ives J, Horne LN, Fortier K, Carbonari DM, Hennessy S, Cardillo S, Reese PP, Reddy KR, Margolis D, Apter A, Kimmel SE, Roy J, Freeman CP, Razzaghi H, Holick CN, Esposito DB, Van Staa TP, Bhullar H, Strom BL. Safety of saxagliptin: rationale for and design of a series of postmarketing observational studies. Pharmacoepidemiol Drug Saf. 2012;21(11): 1202-15.

26. Schelleman H, Bilker WB, Brensinger CM, Wan F, Yang YX, Hennessy S. Fibrate/Statin initiation in warfarin users and gastrointestinal bleeding risk. Am J Med. 2010;123(2):151-7.

27. Schelleman H, Bilker WB, Brensinger CM, Wan F, Hennessy S. Anti-infectives and the risk of severe hypoglycemia in users of glipizide or glyburide. Clin Pharmacol Ther. 2010;88(2):214-22.

28. Kahn MG, Raebel MA, Glanz JM, Riedlinger K, Steiner JF. A pragmatic framework for single-site and multisite data quality assessment in electronic health record-based clinical research. Med Care. 2012;50(Suppl):S21-29.

29. Brown JS, Kahn M, Toh S. Data quality assessment for comparative effectiveness research in distributed data networks. Med Care. 2013;51 (8 Suppl 3):S22-29.

30. Baron JA, Lu-Yao G, Barrett J, McLerran D, Fisher ES. Internal validation of Medicare claims data. Epidemiology. 1994;5(5):541-4.

31. Ray WA, Griffin MR. Use of Medicaid data for pharmacoepidemiology. Am J Epidemiol. 1989;129(4):837-49.

32. Al Kazzi ES, Hutfless S. Better big data. Expert Rev Pharmacoecon Outcomes Res. 2015;15(6):873-6.

33. Cai L, Zhu Y. The challenges of data quality and data quality assessment in the big data era. Data Sci J. 2015;14:2.

\section{Submit your next manuscript to BioMed Central and we will help you at every step:}

- We accept pre-submission inquiries

- Our selector tool helps you to find the most relevant journal

- We provide round the clock customer support

- Convenient online submission

- Thorough peer review

- Inclusion in PubMed and all major indexing services

- Maximum visibility for your research

Submit your manuscript at www.biomedcentral.com/submit 